for the while disobedient as well as restless, and under the influence of which the higher muscular acts-walking, writing, handling, speaking--becomeawkward, difficult, and uncertain. Here is an affection which is all one with the so-called "St. Vitus's dance" of the vulgar, the so-called "chorea" of the learned. And, looking at it from this point of riew, we obtain,just as in the case of hysteria, not merely a picture of what it is like, but a suggestion as to its management.

But in spite of the pleadings of common sense, there is small hope of change. Not in chorea alone, but in other diseases as well, there is the common speech on the one side and our technical "nomenclature of disease" on the other, and as yet they show no tendency to come together or to hold parley. The inconvenience and inaccuracy of the word typhoid have often been pointed out, yet no non-professional person will speak of "enteric fever" or even comprehend what it means. The identity of scarlet fever and scarlatina we are for ever insisting upon, yet, in spite of all protest and to their own danger, the people persist in maintaining a distinction between the two. And similarly, it is to be feared, we shall still cherish our own professional chorea and marvel at the blindness of the community in respect of it; the people will still speak of St. Vitus's dance, associating it less with their own nurseries than with burlesque descriptions in books or the miracles and fanaticism of the Middle Ages. Yet, surely, in no department of medicine is this want of touch and sympathy more mischievous than in the functionalnervous disorders of the young. What is needed for the alleviation, and still more for the diminution, of these common diseases of civilisation, singularly bare as they are of drug remedy, is first an intelligent understanding among the people of their real source and nature, and next the co-operation of parent or teacher on the one hand and medical man on the other with a view to their prevention or cure. But no such understanding or co-operation is possible so long as this pernicious barrier between ourselves and the community is allowed to exist. It was set up ages ago to shelter mystery and pretence, and whether from the one side or the other, be he layman or doctor, he does a good and a seasonable work who will help to pull it down.

Christmas Eve, 1885.

\section{A SUCCESSFUL CASE OF}

\section{GASTROSTOMY FOR THE REMOVAL OF A LARGE MASS OF HAIR FROM THE STOMACH.}

By J. KNOWSLEY THORNTON, M.B., C.M., SURGEON TO THE SAMARITAN FREE HOSPITAL.

I HAVE waited to publish the full details of this very remarkable case until sufficient time has elapsed for any after-troubles to declare themselves; none have appeared, and the patient has enjoyed good health since the operation, and still continues to do so. In reply to a letter of inquiry, she writes: "I have no discomforts that can be attributed to the operation."

Early in 1884, C. H. J_, aged eighteen, single, was sent to me by my friend Mr. Symonds, of Oxford, for an opinion as to an abdominal tumour from which she had for some time suffered. She had already been seen by several other medical men, and very various views had been expressed as to the nature of the tumour, perhaps the most common one being that it was malignant. After in vain attempting to get any satisfactory history from either the patient or her mother, I made a very careful examination, and came to the conclusion that it was an accumulation in the colon. therefore advised frequent doses of castor oil and the use of very lurge enemata. This treatment was thoroughly tried by Mr. Symonds, with the result of giving her much pain and pulling her down a good deal, but without reducing the swelling. She therefore came to see me again, and brought with her a small concretion of hair and fæcal matter which she had passed while under the above treatment. A further examination confirmed my original opinion, and she nuw informed me that for some years she had been in the habit of "eating the combings of her hair and her sewingcotton ends to clean her tongue." The question now arose, Is this mass in the stomach or transverse colon? She bad suffered to some extent from indigestion, but there had been no very marked sickness or pain, and, moreover, there was the small concretion of fæces and hair. I concluded that the mass was in the colon, and advised another prolonged attack upon it with castor oil and enemata, promising, if they failed, to take her into the Samaritan Hospital and perform abdominal section. I thought it was possible, if the mass were in the colon, that after opening the abdomen it might be gradually forced along into the rectum and extracted; at the same time I was quite prepared to open either the stomach or colon if necessary.

The treatment failing to produce any result, and the patient being much weakened by the purging and enemata, her friends earnestly begged for operation, and she was admitted under my care on May 2nd, 1884. A fresh examination revealed no change in the size or position of the mass, and accordingly on May 6th, after the administration of methylene by Mr. Malcolm, I proceeded, with the assistance of Mr. Meredith, and in the presence of Mr. Symonds, Dr. John Homans of Boston, U.S., and many others, to perform the following operation:-Parietes incised in the middle line, the incision beginning two inches above the umbilicus and passing on its left to one inch below it. Stomach exposed, greatly distended by solid mass, which was evidently moulded to the shape of the viscus. Some omentum adherent to the surface of the stomach and to the parietes separated and ligatured. Incision extended two inches further below the umbilicus. Space between distended stomach and parietes carefully packed all round with carbolised sponges. Anterior surtace of stomach grasped and a large fold of the great curvature brought out between the lips of the abdominal incision. Another layer of sponges packed orer the raw edges of the wound round this fold. The fold transfixed and incised by a transverse incision five inches long, care being taken to avoid vessels as far as possible; a few spouted, but were easily controlled by pressure forceps. The mass of hair was at once seen, filling and distending the stomach, and was extracted by a vulsellum with a slight turning movement. The mucus was carefully wiped away all round, as the mass came out, with carbolised sponges, and the cavity of the stomach was at once thoroughly cleansed with them. A large carbolised sponge was then laid in the stomach to keep the edges of the wound in position for suture and prevent accumulation of blood in the organ. Fifteen sutures of fine carbolised silk were then introduced through all the coats, the needle being slanted through the wall so as to come out just at the inner edge of the mucous membrane, which was much inclined to curl. These interrupted sutures were passed so as to control the cut vessels, and no ligatures were used. Another row of similar sutures was then passed between each of the deep sutures, but only through the peritoneum. The deep sutures entered the peritoneal coat about a quarter of an inch from the edge of the incision, and were $a$ third of an inch apart; the superficial sutures were entered at about the same distance from the edge, and ran along just under the peritoneum. When these were all in place the sponge was removed from the stomach, and they were tied, the deep first and then the superficial. These two rows caused some inversion of the peritoneum, and the two outer and upper peritoneal edges of the depression thus formed were brought together by a continuous suture of very fine carbolised silk. There had been no escape of blood or other material into the peritoneum, and no exposure of its contents to chill from the spray. The closed wound measured exactly three inches. The sponges used for the mucus and for the interior of the stomach were kept quite separate from those used for the peritoneum. During the suture of the external wound the nurse was made to count the sponges aloud, my usual custom in ovariotomy. The usual gauze dressing, with straps, was employed. There was no drainage. When the patient was placed in bed, after a two hours'operation, the pulse was 100 , and the vaginal temperature $98^{\circ} 2^{\circ}$.

The after-treatment differed in no way from that which $I$ adopt after ovariotomy and similar operations, except that the stomach-feeding was only commenced on the afternoon of the second day-i.e., forty-eight hours after operation-and was then one teaspoonful of ice-water and milk, equal parts, every half hour. The quantity was gradually increased till the afternoon of the next day, when she was able to take two ounces every hour. On the sixth day three ounces were given every two hours. On the fourteenth day cornflour was added to the diet, on the fifteenth day some crumbled bread, and then gradually an ordin ary light 
diet was allowed. During the first week three ounces of beef-tea were injected into the bowel every three hours, with twenty drops of laudanum every six hours, and during certain complications now to be described port wine and quinine were added to these injections.

In the early morning of the day after the operation there was some retching, which occasioned unusually severe pain about the umbilicus; laterin the day, hiccough, with vomiting of some brownish fluid, took place; the temperature rose to $100.6^{\circ}$, and the pulse to 126. She still complained of great pain about the umbilicus, which the opium failed to relieve. I had heard in the course of the morning that the nurse who had charge of the sponges had, in spite of the counting at the operation, found her number one short on the previous evening. I now began to have some doubt myself, failing to recollect the removal of a sponge which I had placed under the upper part of the incision while tying the lower parietal sutures. At 2.30 P.M. Mr. Meredith gave the patient some methylene, and under the spray I removed a few sutures, and at once came upon the missing sponge full of dark serum and firmly adherent to the surfaces with which it was in contact. On examination afterwards, and on section, it was found to be already, in less than twenty-four hours, permeated to some depth with organising lymph. Before again closing the incision I passed sponges into the pelvis, and into both loin pouches, and found all dry and elean. I also examined the wound in the stomach, and found it perfectly quiet and free from redness or swelling. The external wound was closed and dressed as before. At the conclusion of this second operation the vaginal temperature was $101.4^{\circ}$; pulse 120 . Pounded ice in mackintosh was placed on the head, and next morning the temperature was $99 \cdot 6^{\circ}$ and the pulse 104. All went well after this till the morning of the fourth day, when the ice was removed from the head, the temperature being $984^{\circ}$ and the pulse 84 . In the course of the day she began to complain of pain in the right side of her neck, and the parotid swelled. Later there was soreness of throat on that side and difficulty in swallowing. The evening temperature was $101.4^{\circ}$; pulse 120 ; respiration 22. The ice-water cap was put on. 'On the following morning glycerine and belladonna were applied on cotton-wool all over the swelling. Temperature $1018^{\circ}$; pulse 112 . In the afternoon the pain and swelling had become so great that I iucised the gland, under the spray. There was no pus, but free oozing of blood and serum reduced the swelling and pain. Evening temperature $102^{\circ}$; pulse 120 . The following day (the sixth after operation), the temperature rose to $103^{\circ}$, and pulse to 128 . The left parotid began to swell, and was at once covered with glycerine and belladonna. On the following day (the seventh) the bowels were well cleared by enema, and on the eighth day the abdominal wound was dressed and the sutures removed, the whole wound having united perfectly by first intention. The right parotid, which had been dressed daily, began on this day to discharge a little pus. The swelling had entirely disappeared, but the left gland, which had not been incised, remained swollen and painful. On this day there was a sudden increase in the quantity of urine, nearly five pints being passed in twenty-four hours; doubtless this was hysterical, the hair-eating being another manifestation of the same complaint. From this time improvement was rapid, the only trouble being occasional attacks of polyuria. At the end of the second week the swelling of the left parotid had quite gone, and on the following day my incision into the right one healed. She was moved into the convalescent ward on the twentieth day, with a normal pulse and temperature, and was up four days later, leaving the hospital twenty-nine days after the operation quite well. From first to last she had no unfavourable symptom or pain in the abdomen, and when she left there was no tenderness on pretty firm pressure in the epigastrium. Now she is strong and well, and has quite given up eating hair. The mass removed from the stomach was almost entirely matted hair, moulded into the shape of the organ, and it weighed two pounds.

I have never been able to make up my mind whether to attribute the parotid swellings directly to the operation, or whether to look upon them as a chance attack of mumps, from which she had not previously suffered. Most of the cases of this kind which I have either seen or heard of have been distinctly of septic origin; but in this case, certainly, there were no other symptoms pointing in this direction, and I do not believe that the right gland would have suppurated any more than the left, had I not been in too great a hurry to incise it and put in a rubber drainagetube. Moreover, I have had two other cases in my own practice, which have got quite well without the patients suffering from other symptoms of septicæmia, one case rapidly subsiding without treatment, and one suppurating and requiring incision and drainage. On the other hand, in the particular case under consideration, it would not be at all surprising if the swellings were of septic origin, for many of the sutures in the stomach passed through the edge of the mucous membrane and must have been exposed to the absorption of septic material. The sponge incident is one more to be added to the long list of cases in which foreign bodies have been left in the abdomen in abdominal surgery; it is the second time the accident has happened in my own practice, and in both cases it was fortunately discovered in time to save the life of the patient. ${ }^{\text {W }}$ When I hit upon the plan of making the nurse count the sponges aloud, I thought I should in future be quite safe, but it seems that the only way in this case, as in many others, is to do it oneself, if one wants to be sure that it is well done. Had I been as responsible as she was, I certainly could not have gone placidly to bed and slept comfortably as she did, telling me casually of the lost sponge eighteen hours after she missed it. The freedom from serious hæmorrhage while making so large a wound in the stomach, and the immediate closure of the wound without any after-troubles from the presence of such a number of silk sutures in the stomach wall, would be surprising had we not already learnt from the resections for malignant disease how much surgery this organ will tolerate.

Shortly after the recovery of my own case I heard that Dr. Schönborn of Königsberg had published a somewhat similar case in Langenbeck's Archives (1883, vol. xxix., p. 609). His incision into the stomach was about the same length as mine, and was closed by two rows of silk sutures. They must have been very close together, for he used sixtyfive, and I only used thirty. The operation was thoroughly antiseptic, salicylic spray being used. The patient was quite well in three weeks, and able at that time to eat and digest any ordinary food, even beefsteak. The mass of hair removed was much smaller than in my case, only weighing nine or ten ounces. He gives an engraving of it, natural size. Illustrations of the masses accompany several of the records of cases in which similar masses were discovered after death, and they are all more or less moulded into the shape of the stomach. Schönborn notes in his case that the mucous membrane of the stomach was quite healthy, as it was also in my case. It is very strange it should be so, after long distension with these great rough foreign bodies. The cases of Professor Schönborn and myself are, I believe, the only two which have been successfully treated by operation. Several other cases have been described from postmortem examination, most of the patients having died from peritonitis, which was in some of them due to ulceration and perforation. Bandamant published a case in the Journal de Médecine (vol. ii., p. 507, 1779), the patient being a male who had from a very early age been known to swallow horse-hair; he died, after great suffering, at the age of sixteen. Pollock published in the Pathological Transactions (1851-52, p. 327) the case of a girl, who died at the age of eighteen, with a mass of hair in the stomach measuring 6 in. by $3 \frac{3}{4}$ in., and a smaller mass in the duodenum. She had been known to eat hair since she was three years old. The illustration accompanying this is very like the mass I removed. George May, jun., published a similar case, I believe, in 1865; but I have been unable to find it. Ritchie published one in the Edinburgh Monthly Journal (vol. ix.); the patient, a female, died at twenty-one, and the mass weighed $21 \mathrm{oz}$. Russell published one in the Medical Times (1869), which is, perhaps, the most remarkable of the series; the woman died at thirty-one after an abortion, and a matted mass of hair was found in her stomach weighing $4 \mathrm{lb} .7 \mathrm{oz}$., and dragging the pylorus down into the pelvis; it had been growing for seventeen years, yet she did not seem to have suffered much from its presence, and there was only one small ulcer in the stomach. This case led Inman to publish in the same journal a short note of a case which he had heard of in the practice of Dickinson of Liverpool, the patient, also a female, dying at thirty-four, with symptoms of obstruction. In the same year (1869) Best recorded a case in the British Medical Journal, the patient, also a

1 For note of first case see Proceedings of Medical Society of London, vol. v., p. 37,1881 ; also, report of the meeting, THR LArcET, Dec. 13th,
1879, vol. ii., p. 875 . 
female, being thirty when she died, and the mass weighing $30 \mathrm{oz}$. It is obvious from these records that the condition tends to a fatal termination if not relieved, and its successful treatment is another triumph for the abdominal surgery of our day.

\section{COMBINED DISEASE OF THE POSTERO- EXTERNAL AND LATERAL SPINAL} TRACTS.

BY C. W. SUCKLING, M.D. LoNd., M.R.C.P., PHYSICLAN TO THE QUEEY'S HOSPITAL, BIRMINGHAM.

B. G-- a labourer, aged sixty-one, was admitted into the workhouse infirmary on August 18th, 1885, complaining of weakness and pains in the legs. No family history of importance could be elicited. He has been a free drinker and much exposed; in 1879 he contracted syphilis. His present illness commenced about two and a half years ago with pains in the legs, more severe in the right, shooting and paroxysmal in character. He has been unable to work for a year and nine months. In July, 1884, he was in the infirmary, and it is recorded on his case papers that he suffered at that time from constipation and "double sciatica," that there were no tender spots in the course of the nerves, and that the reflexes in the lower extremities were slightly increased. In October, 1884, it was observed that the symptoms were those of locomotor ataxy, although the knee-jerk was increased. The Romberg symptom was present, and the gait was somewhat ataxic. The patient was not seen again until his readmission in August last, he then stated that during the last few months his legs had been getting very weak, so that he could searcely walk at all At times also he had suffered from girdle pain and severe paroxysms of shooting pains in both legs, and had noticed that he could not control them-they would "kick out"; but latterly his toes caught the ground in walking. He had never suffered from vomiting, pain in the head, or vertigo. For the last few weeks he had been unable to hold his urine, and it dribbled at times.

At the present time the patient can walk with sticks, but he has a difficulty in lifting the toes, which drag, and is quite unable to point them owing to weakness of the extensor muscles. He lifts the feet rather high from the ground and brings the heels violently down, the gait being a combination of the spastic and ataxic types. There are marked swaying movements when he attempts to stand with his eyes closed. He complains of numbness in the legs, and there is complete analgesia and thermal anæsthesia in both; tactile sensibility is perfect both as regards localisation and differential sensibility. There is no well-defined line of demarcation of the analgesia upwards. The muscular sense is unimpaired; he can tell the difference between half ounce and one ounce weights suspended from the toes, knows the position of his limbs, and executes any required movement with precision, his eyes being closed. The plantar, cremasteric, abdominal, and epigastric reflexes are very well marked. The knee-jerk is exaggerated, and vibration of the patellar is marked when the quadriceps extensor is suddenly put on the stretch by depression of the patella. There is slight ankle-clonus on both sides, but no front tap contraction. The left cremasteric reflex is absent. Spontaneous jerking movements of the legs frequently occur and trouble him a great deal. There is no pain in the back at present, no deformity or tenderness anywhere on percussion, and no rigidity. There is myosis of both pupils, which refuse to respond to light, but do so readily to accommodation. The fundus oculi is normal on both sides. Slight incoordination is observed in the upper extremities; he does not guide the fingers to different parts of the face very accurately. The urine is ammoniacal ; it contains no albumen or pus, There is, however, considerable paresis of the bladder, the urine constantly dribbling. There are no tremors and no rigidity of the legs; no bedsore or other trophic lesion.

As to the diagnosis in this case. Myelitis in the upper part of the lumbar enlargement would account for the bladder trouble and for the increase of the reflexes below the cremasteric. But this is excluded by the great predominance of the irritative phenomena, and by the very gradual onset of the paresis (two years and a half). The increase of the reflexes was observed before the paresis appeared. Meningo-myelitis or pacchymeningitis with secondary implication of the cord would explain all the irritative phenomena, and by involving the postero-external and lateral columns would account for the ataxic and paretic symptoms. The pupil symptoms would, however, remain to be accounted for. All the symptoms are explained on the supposition that the case is one of combined primary sclerosis of both postero-external and lateral columns. At first the symptoms were those of locomotor ataxy-double sciatica, ataxic gait, and Romberg symptom; then symptoms indicative of implication of the lateral columns, increase of reflexes, spasmodic jerkings, and paresis. The paralysis of the bladder is a point against the above diagnosis, for a moderate degree only of incontinence is observed in tabes, complete paralysis being rare, while in lateral sclerosis bladder symptoms are much less frequently present than in tabes. Charcot insists that double sciatica is always symptomatic, and that its causes are spinal diseases-e.g., locomotor ataxy and meningo-myelitis, diabetes, cancerous disease of the spine causing pressure on the nerves, and disease of the nerves themselves. Westphal reported five cases of this affection in the Archiv fir Psychiatrie (vols. viii. and ix.). He believes that the lesion does not spread directly from the posterior to the lateral columns, but that the lesions of the two columns are independent. From his cases he concludes that when the lateral columns are affected the symptoms of ataxia are replaced by those of paresis, and not by contracture. In my case no rigidity is present.

\section{CASE IN WHICH A LOUD SPLASHING SOUND WAS PRODUCED SYNCHRO- NOUSLY WITH CARDIAC ACTION. ${ }^{1}$}

BY WILLIAM RUSSELL, M.D., M.R.C.P.E., LECTURER ON PATHOLOGY IN THE SCHOOL OF MEDICINE, EDIKBURGH; PHYSICIAN TO THE NEW TOWN DISPENSARY, ETC.; AND

J. C O M A C K SM I TH, M. B., C. M., PHYSICIAN TO THE COWGATE DISPENSAHY.

Mr. B-_, aged twenty-four, a student of medicine, called on Dr. Cormack Smith, of Abbey-hill, on the evening of June 14th, 1885, complaining of pain in the præcordial region and in the region of the left scapula, not extending below its angle, and also of pain in the left arm as far as the elbow. The pain was "numb" in character. In addition; there was a feeling of constriction at the præcordia, and inspiration was so painful that only "half breaths" could be taken. The pain had come on suddenly after dinner, the dinner hour having been 4 P.M. It was so acute that he went and lay down, and he had no sooner done so than the sound to which we shall have specially to refer became audible to himself. The stomach had been out of order for some days previously; there had been an absence of the normal relish for food, and the bowels had been confined. He had never had any illness of importance, and there was no rheumatic history and no history of special injury, although he had had a somewhat severe fall from his bicycle a few years before. There is, however, one interesting point in the history. Three years ago, during the night, a friend who shared his bed was awakened by a noise evidently proceeding from our patient's inside. Becoming alarmed, he roused his friend, and he, with his medical knowledge, referred the sound to his heart, as it was synchronous with its pulsation. It was not accompanied by pain, and in the morning the sound had disappeared. He was quite satisfied that the sound at that time resembled exactly that which we shall presently describe. The only explanation he could offer as a possible cause was that he had walked very rapidly from South Queensferry the previous day.

When Dr. Smith first saw him the pulse was 84 , and the temperature was slightly raised, but had fallen to normal the following day. He was kept in bed. On June 21st he was seen by both of us, and we took the following notes of his case. The pulse was 64, regular, small, and thready, readily compressed and obliterated. There was no albumen 